\title{
A Priori Analysis of Flamelet-Based Modeling for a Dual-Mode Scramjet Combustor
}

\author{
Jesse R. Quinlan* and James C. McDaniel ${ }^{\dagger}$ \\ Tomasz G. Drozda ${ }^{\ddagger}$ \\ University of Virginia, Charlottesville, VA, 22904 \\ NASA Langley Research Center, Hampton, VA, 23681 \\ Guilhem Lacaze ${ }^{\S}$ and Joseph Oefelein $₫$ \\ Sandia National Laboratories, Livermore, CA, 94550
}

\begin{abstract}
An a priori investigation of the applicability of flamelet-based combustion models to dual-mode scramjet combustion was performed utilizing Reynolds-averaged simulations (RAS). For this purpose, the HIFiRE Direct Connect Rig (HDCR) flowpath, fueled with a JP-7 fuel surrogate and operating in dual- and scram-mode was considered. The chemistry of the JP-7 fuel surrogate was modeled using a 22 species, 18-step chemical reaction mechanism. Simulation results were compared to experimentally-obtained, time-averaged, wall pressure measurements to validate the RAS solutions. The analysis of the dual-mode operation of this flowpath showed regions of predominately non-premixed, high-Damköhler number, combustion. Regions of premixed combustion were also present but associated with only a small fraction of the total heat-release in the flow. This is in contrast to the scram-mode operation, where a comparable amount of heat is released from non-premixed and premixed combustion modes. Representative flamelet boundary conditions were estimated by analyzing probability density functions for temperature and pressure for pure fuel and oxidizer conditions. The results of the present study reveal the potential for a flamelet model to accurately model the combustion processes in the HDCR and likely other high-speed flowpaths of engineering interest.
\end{abstract}

\section{Introduction}

$\mathrm{T}^{\mathrm{H}}$ HE transition of a dual-mode scramjet engine from dual-mode operation to scram-mode operation occurs in flight as a vehicle accelerates along its flight trajectory. During this transition the combustion changes from primarily subsonic to largely supersonic. Understanding and predicting the physics of this transition is important to maintaining robust engine operation. Experimental investigations of dual-mode transition are typically limited by the inability of hypersonic test facilities to vary the flow Mach number in real time through the transition process. Despite these difficulties, experimentalists have successfully ground-tested several dual-mode scramjet engines at discrete Mach numbers, typically in support of flight test programs. Some of these experiments include the HyShot flight experiment, ${ }^{1,2}$ the X-43 flight program, ${ }^{3,4}$ the HIFiRE experiments, ${ }^{5,6}$ and the National Center for Hypersonic Combined Cycle Propulsion (NCHCCP) experiments. ${ }^{7}$ Several research efforts have also subsequently been directed at computationally investigating these experiments via both Reynolds-averaged simulations (RAS) ${ }^{8,9}$ and large eddy simulations (LES). ${ }^{10-12}$ The computational efforts have focused primarily on hydrogen combustion experiments and utilized either flamelet models or reduced finite-rate kinetics to model combustion. Computational investigations of hydrocarbon-fueled engines have been largely limited to RAS due to the increased computational costs associated with hydrocarbon chemical kinetics models.

While RAS remains the workhorse of the scramjet community, LES offers substantial scientific benefit for simulating high-speed flows. Specifically, and in contrast to RAS, LES enables simulations of the majority of

\footnotetext{
*PhD Candidate, Department of Mechanical and Aerospace Engineering, 122 Engineer's Way, and AIAA Student Member.

$\dagger$ Professor, Department of Mechanical and Aerospace Engineering, 122 Engineer's Way, and AIAA Associate Fellow.

¥Aerospace Engineer, Hypersonic Airbreathing and Propulsion Branch, 22 Langley Blvd, and AIAA Senior Member.

$\S$ Member of the Technical Staff, Combustion Research Facility, 7011 East Avenue, and AIAA Member.

I Distinguished Member of the Technical Staff, Combustion Research Facility, 7011 East Avenue, and AIAA Associate Fellow.
} 


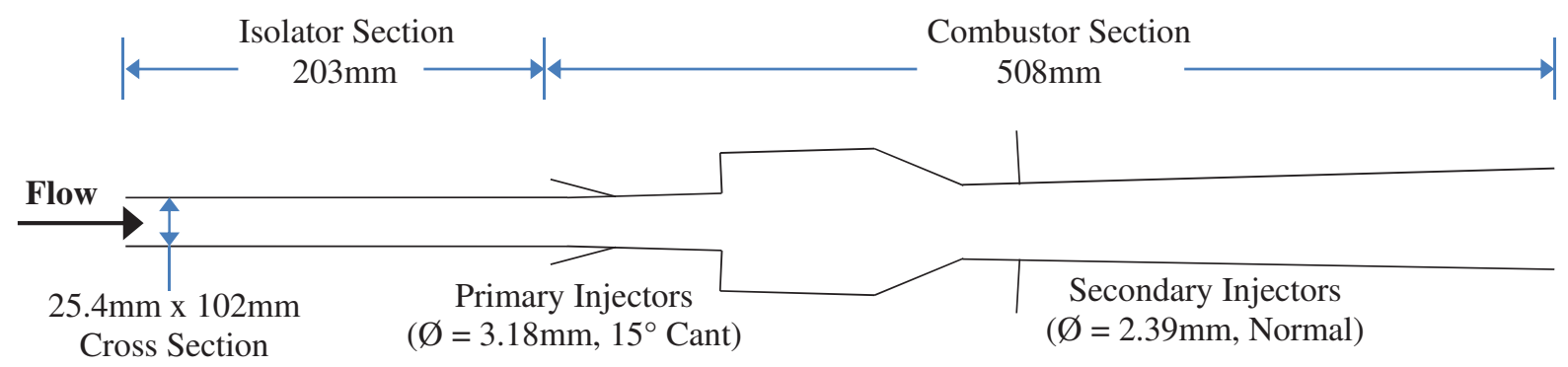

Figure 1. Side view and key dimensions of the HDCR combustor flowpath, where $\oslash$ denotes the internal diameter of the injectors.

turbulence length and time scales. This difference makes LES particularly well-suited to elucidate the physics of dual-mode transition flows, which typically contain strong shock trains, complex shock-boundary layer interactions, significant regions of separated flows, and mixing-limited chemical reactions. Unfortunately, LES is significantly more computationally expensive with the computational costs increasing by an order of magnitude or more as compared to RAS. For simulations utilizing finite-rate chemistry the computational costs are further exacerbated by the stiffness associated with solving combustion rate equations. Nevertheless, the computational cost of combustion chemistry can be reduced by several approaches. Some common approaches include reducing chemical reaction mechanisms, ${ }^{13,14}$ in-situ adaptive tabulation methods, ${ }^{15}$ and flamelet models. ${ }^{16-18}$

In recent years, researchers have had success with applying incompressible flamelet models to flows of increasing complexity using both RAS and LES. Since flamelet models rely on pre-computing the entire thermochemical statespace, the total simulation cost is largely insensitive to the complexity of the chemical reaction mechanism employed. However, the development of a compressible flamelet model formulation has gone unrealized, despite the potential for making LES of high-speed, compressible, reacting flows affordable.

Motivated by prior research efforts and the potential for routine, affordable LES of hydrocarbon-fueled dual-mode scramjet combustion, this paper considers the applicability of flamelet models ${ }^{16,17}$ to simulations of a dual-mode scramjet combustor fueled by a JP-7 surrogate. The current analysis is performed in an a priori fashion based on RAS of the HIFiRE Direct Connect Rig (HDCR). This RAS utilizes a finite-rate chemical kinetics model from which typical quantities defining a flamelet, such as mixture fraction and progress variable, can be calculated. While this study focuses mainly on the ability to simply replace finite-rate kinetics with flamelet models for problems of engineering interest some fundamental assumptions made in deriving flamelet-modeling theory are also evaluated for both dualmode and scram-mode conditions. In doing so, the flow field is further characterized using flame and combustion mode indices. Finally, the effects of compressibility and heat losses on the combustion were evaluated, and the bounding conditions for a flamelet table representative of the thermo-chemical state-space enveloped by the HDCR combustor flow field were investigated.

\section{Physical Flow}

The HDCR was a ground-based experiment previously conducted at NASA Langley Research Center (LaRC) in support of the HIFiRE flight experiments. ${ }^{19}$ The test article comprised a cavity-based hydrocarbon-fueled scramjet combustor, which was tested in a direct-connect fashion in the NASA LaRC Arc Heated Scramjet Test Facility. ${ }^{20}$ The model included a constant-area cross-section isolator duct attached to a combustor containing five stages of fuel injectors. During the experiment, only the primary and secondary injectors located upstream of the cavity and downstream of the cavity closeout, respectively, were fueled. A mold line of the flowpath is shown in Fig. 1, in which relevant dimensions and injector locations are illustrated.

The HDCR was fueled by a JP-7 surrogate consisting of 36\% methane and $64 \%$ ethylene by volume. Experimental objectives included demonstrating scram-mode operation of the flowpath at an equivalence ratio, $\phi$, of 1.0 and combustion efficiency greater than 0.7 and simultaneously developing a fuel distribution schedule to safely operate the subsequent flight engine through dual-mode to scram-mode transition. ${ }^{21}$ For the purpose of the current investigation, dual-mode operation is defined by a combustion-induced pressure rise upstream of the primary fuel injectors and scram-mode operation is defined by minimal combustion-induced pressure rise upstream of the primary fuel injectors 
and presence of supersonic combusting flow (specifically, a one-dimensional combustor Mach number greater than one). Consequently, the leading combustion-induced compression shock anchors either upstream or downstream of the primary injectors for dual- and scam-mode operation, respectively. Based on the estimated flight trajectory, the transition was expected to occur between flight Mach numbers of 6-8. Two computational fluid dynamics (CFD) simulations of the HIFiRE inlet, bounding these flight Mach numbers, were performed to estimate the corresponding Mach numbers at the inlet to the isolator for the direct-connect experiments. The results obtained from the CFD simulations showed that the facility nozzles with Mach numbers of 2.51 and 3.46 produced isolator flows appropriate for the dual-mode and scram-mode experiments, respectively. ${ }^{22}$ The total enthalpy of each of the two flows was set to match that of the corresponding flight Mach number. Data collected during the experiments included wall temperatures, heat fluxes, and static pressures. The flowpath was outfitted with 144 static pressure ports, 19 flowpath surface thermocouples, and 4 heat flux gages.

\section{Reynolds-Averaged Simulations}

Since the experiments only provided wall-based measurements, CFD simulations were conducted to further understand the flow physics and the combustion processes characterizing the HDCR flowpath. For this purpose, two experimental conditions corresponding to dual- and scram-mode operation of the flowpath were chosen. The dual-mode cases were tested at a flight Mach number of 5.84 and a total equivalence ratio of 0.65 , whereas the scrammode cases were tested at a flight Mach number of 8.0 and a total equivalence ratio of 1.0. The total equivalence ratio was split between the primary and secondary injectors, respectively, as 0.15 and 0.5 for the dual-mode cases and as 0.4 and 0.6 for the scram-mode cases. Hereafter, simulation cases will be referenced using a case identifier that reflects the operational mode, the flight Mach number, and the imposed wall boundary conditions, as shown in Table 1. For example, case $D 584 A$ signifies dual-mode operation, $D$, at a flight Mach number of 5.84 with adiabatic walls, $A$. Similarly, case $S 800 I$ signifies scram-mode operation, $S$, at a flight Mach number of 8.00 with one-dimensional heatconduction wall boundary condition, $I$.

\section{A. Numerical Formulation}

All simulations were performed using the thermally-perfect Viscous Upwind aLgorithm for Complex flow ANalysis Computational Fluid Dynamics (VULCAN-CFD) code. ${ }^{23}$ VULCAN-CFD is a structured grid finite-volume solver that is extensively used for high-speed combustion simulations using RAS techniques. For the current study, a 6.6 million cell, quarter-geometry, structured grid was used, which is illustrated in Fig. 2. This grid included the facility nozzle. Wall spacings were set for efficient application of wall-matching functions. ${ }^{24}$ At no point in the combustor did the $y+$ value exceed approximately 30 . Symmetry was enforced at symmetric boundaries, and an extrapolation of transported variables was applied at the outflow plane. No-slip conditions were applied at all solid surfaces, and simulations were performed for both adiabatic walls and walls with a variable surface temperature distribution. For the latter case, the surface temperature at each point was determined by solving the local one-dimensional heat-conduction equation given the local wall thickness, thermal conductivity, and back-wall temperature. The governing ReynoldsAveraged Navier-Stokes and scalar transport equations were closed using the blended $k-\omega / k-\epsilon$ turbulence model of Menter, ${ }^{25}$ where $k$ is the turbulence kinetic energy, $\omega$ is the turbulence frequency, and $\epsilon$ is the turbulence dissipation rate. Inviscid fluxes were calculated using the low-dissipation flux split scheme (LDFSS) of Edwards. ${ }^{26}$ The van Leer flux limiter was used, along with a monotone upstream-centered scheme for conservation laws (MUSCL) with

Table 1. Summary of simulated test cases, including flight Mach number, plenum conditions, fuel equivalence ratios $(\phi)$, and wall boundary conditions.

\begin{tabular}{ccccccc} 
Case & $\begin{array}{c}\text { Flight Mach } \\
\text { Number }\end{array}$ & $\begin{array}{c}\text { Plenum Total } \\
\text { Temperature } \\
{[\mathrm{K}]}\end{array}$ & $\begin{array}{c}\text { Plenum Total } \\
\text { Pressure } \\
{[\mathrm{atm}]}\end{array}$ & $\begin{array}{c}\text { Primary } \\
\text { Injector } \phi\end{array}$ & $\begin{array}{c}\text { Secondary } \\
\text { Injector } \phi\end{array}$ & Wall Treatment \\
\hline D584A & 5.84 & 1550 & 14.63 & 0.15 & 0.5 & Adiabatic \\
D584I & 5.84 & 1550 & 14.63 & 0.15 & 0.5 & 1D Heat Conduction \\
S800A & 8.00 & 2570 & 42.19 & 0.40 & 0.6 & Adiabatic \\
S800I & 8.00 & 2570 & 42.19 & 0.40 & 0.6 & 1D Heat Conduction
\end{tabular}


Upstream View

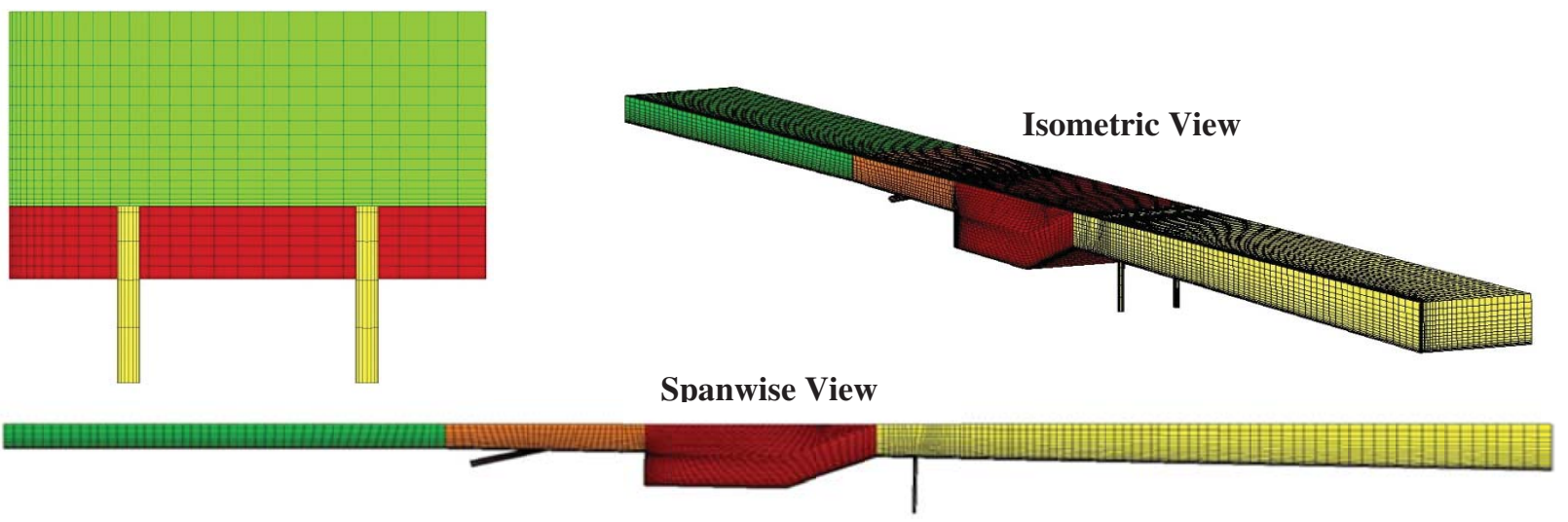

Figure 2. Looking upstream, isometric, and side views of the structured, quarter-geometry, grid used for RAS of the HDCR combustor coarsened four times for visual clarity.

an interpolation coefficient $(\kappa)$ of $1 / 3$. The equations were integrated in pseudo-time using an implicit diagonalized approximate factorization (DAF) scheme ${ }^{27}$ with a maximum local CFL number of 2.0.

Chemistry was modeled using a 22-species, 18 -step reduced chemical kinetics mechanism designed for the combustion of ethylene. ${ }^{28}$ Transport equations for the 22 species were solved implicitly. The species production rates were computed based on the Reynolds-averaged species mass fractions, temperature, and pressure. This modeling approach is often referred to as laminar chemistry assumption. The turbulent Prandtl number was set to 0.89 for each case, and the turbulent Schmidt number was set to 0.325 for the dual-mode cases and 0.25 for the scram-mode cases, as suggested by Storch et al. ${ }^{21}$ Diffusion coefficients were calculated using constant laminar and turbulent Schmidt numbers.

\section{B. Dual-Mode Flow Field}

Comparisons of wall static pressures data obtained experimentally and for dual-mode cases D584A and D584I are shown in Fig. 3a. Both cases agree well with the experimental data and capture the location of the leading oblique shock due to combustor pressure rise. Results obtained for case D584A predict the peak combustor pressure rise and subsequent exit nozzle expansion slightly better than those of case D584I. For this reason and to further simplify analysis by eliminating heat transfer to the walls, case D584A is subsequently used as the baseline dual-mode solution.

Examination of Mach number contours further confirms the dual-mode operation of the flowpath. As illustrated in Fig. 4a, the leading shock due to combustor pressure rise resides upstream of the primary injectors, which is followed by a series of shock reflections. The black line in this figure corresponds to the sonic line and aids in distinguishing regions of subsonic and supersonic flows. The leading oblique shock serves to stabilize flames that anchor near the primary injector orifices. The flow subsequently separates downstream of the primary injectors at the rearward-facing step corner, and a shear layer forms over the recirculating flow within the cavity, that reattaches near the of cavity closeout. Subsequently, the mixture of oxidizer, combustion products, and unburnt fuel originating from the primary injectors mixes with the unburnt fuel injected at the secondary set of injectors. As suggested by the relative fuel equivalence ratios, the secondary injector flames release considerably more heat than the primary injector flames, which is illustrated by chemical heat release in Fig. 5a. The flow is finally expanded through the exit nozzle.

\section{Scram-Mode Flow Field}

For scram-mode operation of the flowpath, simulation results for case S800A demonstrate good agreement with experimental static wall pressure data, while simulation data for case S800I overpredict the peak combustor pressure 

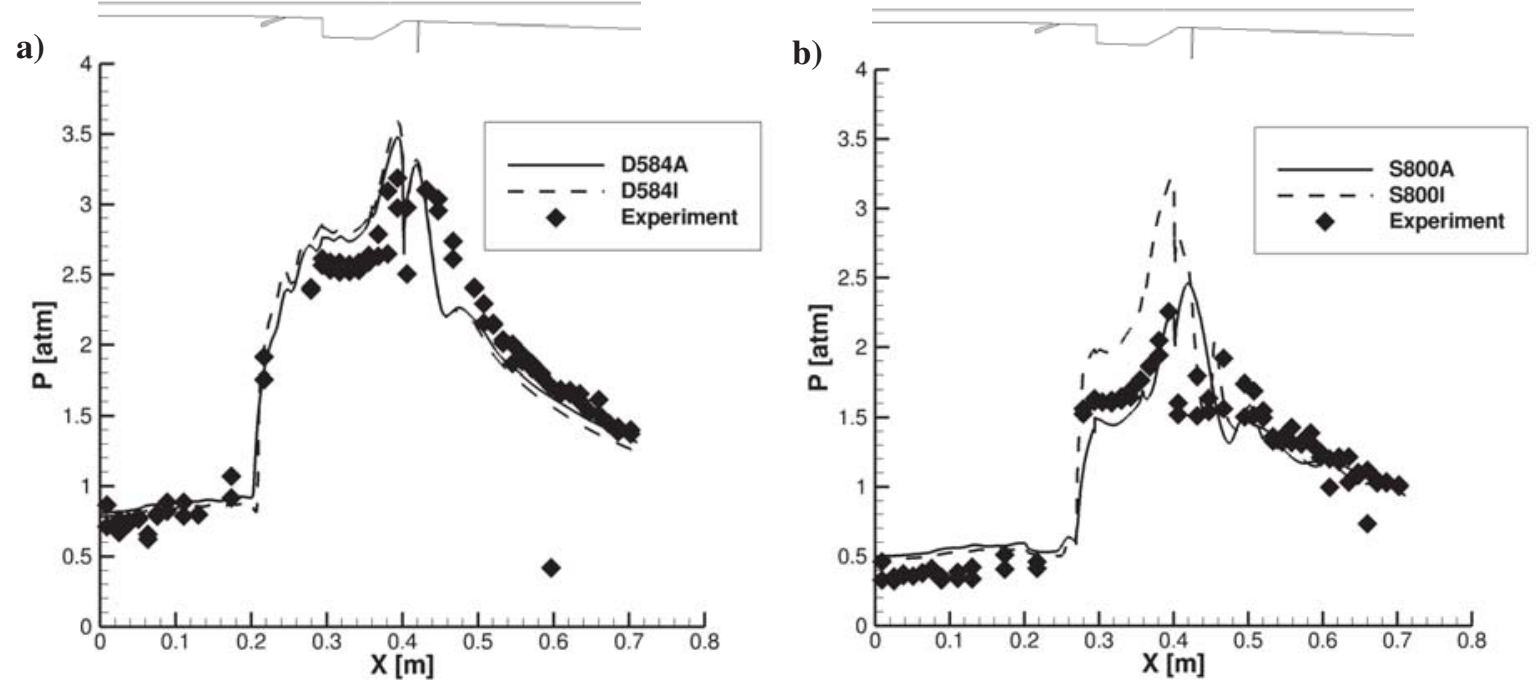

Figure 3. Wall static pressure data versus streamwise direction obtained from simulations and experimentally for dual-mode (a) and scram-mode (b) operation of the HDCR combustor.

by approximately 0.7 atm, as shown in Fig. 3 b. Both solutions predict the pressure drop through the exit nozzle and overpredict the isolator pressure by about $0.1 \mathrm{~atm}$. The differences in these solutions are a direct indication of the sensitivity of the flow field solution to wall heat transfer, which will be discussed as relevant to flamelet modeling in the following section.

Examining Figs. $4 \mathrm{a}$ and $4 \mathrm{~b}$ together further supports previously discussed differences between the dual- and scrammodes. Unlike for the dual-mode solution, the combustion occurs predominantly at supersonic flow velocities. Of further importance are the differences in flame location and structure as suggested by the contours of chemical heat release in Fig. 5b. Whereas in the dual-mode case a strong thin flame anchors directly outside the primary injector orifices, in the scram-mode case the primary injector fuel burns downstream of the injectors in a more distributed fashion. These flames reside behind the leading oblique shock and above the cavity region. It is important to note that the equivalence ratio of the primary injectors is lower for dual-mode than for scram-mode cases, therefore the described flame differences are expected to persist even when the equivalence ratio for dual-mode cases would match that of the scram-mode cases. The secondary injector flames, on the other hand, appear to be of a similar nature to those of the dual-mode case. Differences in flame structure are investigated in more detail in the following section.

\section{Combustion Characterization}

Flamelet models for turbulent combustion assume that within a turbulent combusting flow field are embedded asymptotically-thin locally-laminar flames or flamelets. ${ }^{16,17}$ When the flame chemistry can be assumed to occur much faster than relevant transport processes, the scalar dissipation rate provides the only means of influence for the fluid mechanical processes on the flamelet structure. The flamelet equations may then be derived and used to construct a multi-dimensional manifold prior to a CFD simulation. This manifold can be parameterized by a small number of scalar variables and tabulated. The resulting table may be accessed at runtime to retrieve relevant thermochemical data. Such an approach requires solving transport equations only for the parameterizing variables in place of the generally much larger system of chemical species transport equations, thereby resulting in a significantly less-stiff and less computationally-expensive system of governing equations.

Determining the applicability of flamelet-models for a turbulent combusting flow requires one to consider the extent to which the flow field meets the fundamental flamelet-model assumptions. In the case of non-premixed combustion, for which the flamelet is attached to the surface of stoichiometric mixture fraction and for which the scalar dissipation rate couples the flame dynamics to that of the fluid dynamics, the characteristic chemical time scale must be considerably smaller than that of the representative diffusive and turbulent transport processes. Consequently, 

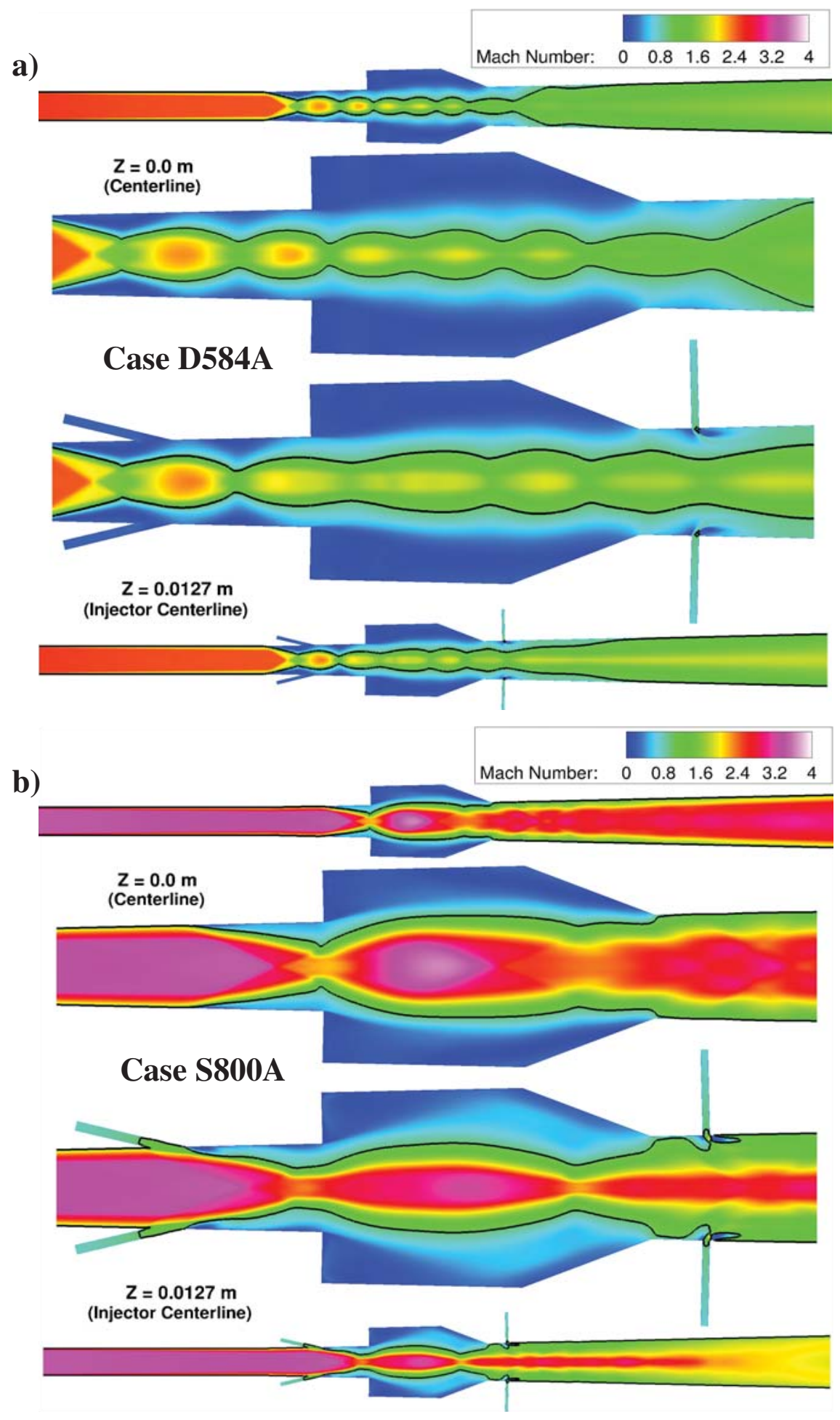

Figure 4. Contours of the Mach number at spanwise center plane and middle injector centerline for cases D584A (a) and S800A (b). Black lines correspond to the sonic line. 

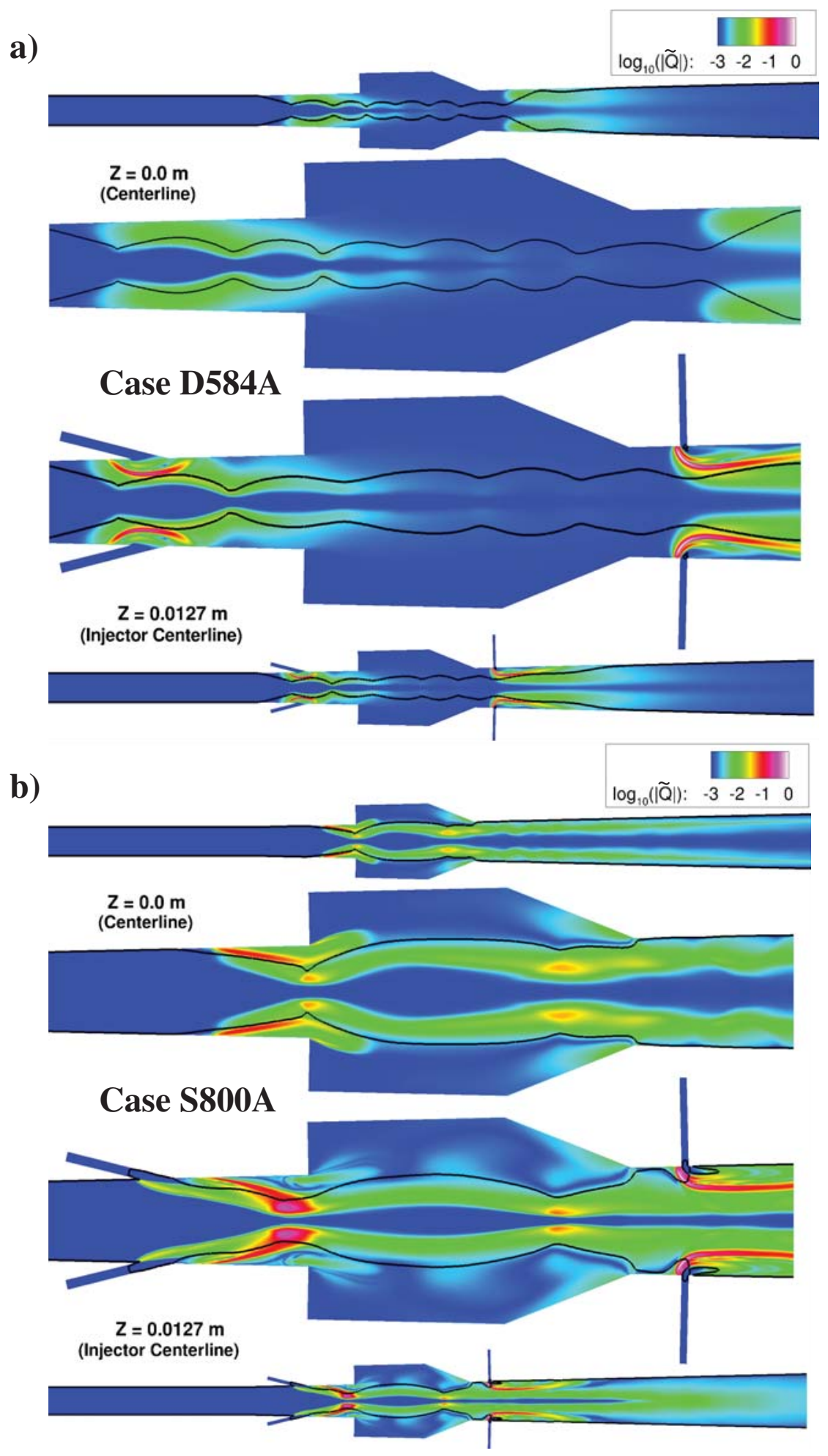

Figure 5. Contours of the logarithm of chemical heat release normalized by its global maximum for simulations D584A (a) and S800A (b). Black lines correspond to the sonic line. 
the Damköhler number (Da),

$$
D a=\frac{\tau_{\text {flow }}}{\tau_{\text {chem }}}
$$

where $\tau_{\text {flow }}$ and $\tau_{\text {chem }}$ are the characteristic flow and chemistry time scales, respectively, must be much greater than unity.

In the case of premixed combustion, the chemical time scale and thermal diffusivity effectively govern the flame thickness, which, in the flamelet regime, must be considerably smaller than the representative turbulent length scales. Consequently, for premixed turbulent flames, the Karlovitz (Ka) number defined as the ratio of a characteristic flame length scale to a characteristic turbulence length scale, should be much less than unity. In most cases, the Kolmogorov scale is used as the representative turbulence length scale.

The primary objective of this section is to use the RAS solutions presented in the previous sections to determine whether the flamelet model assumptions are valid for a dual-mode scramjet combustor. The intent is not to investigate the fundamental aspects of the flamelet models, which could only be addressed via direct numerical simulation, but rather to determine whether the current flow field obtained via RAS can be adequately represented by a flamelet approach.

In doing so, a flame index is first devised to objectively identify regions of chemical reactivity. Once the data is filtered using the flame index, a flame-weighted Takeno index is calculated that distinguishes regions of premixed and non-premixed fueling conditions. Local Da and Ka numbers are subsequently estimated using the approach outlined by Poinsot and Veynante ${ }^{29}$ and Peters. ${ }^{17}$ Borghi diagrams ${ }^{30}$ are constructed for the premixed combustion, and proxy combustion diagrams are devised for the non-premixed combustion using the flame-weighted Takeno index and Da number.

\section{A. Flame Index}

The first step in characterizing the combustion fields is to devise a metric indicative of flame activity, which can be used to identify regions of combustion. The current study uses the approach of Lacaze ${ }^{31}$ who defines a flame index, $f$, as

$$
f(x, y, z)=\frac{\max _{\alpha}\left(\left|\widetilde{\dot{\omega}}_{\alpha}(x, y, z)\right|\right)}{\max _{x, y, z}\left(\max _{\alpha}\left(\left|\widetilde{\dot{\omega}}_{\alpha}(x, y, z)\right|\right)\right)}
$$

where the subscript attached to the maximum operator denotes the quantity over which the operation is performed, $\widetilde{\dot{\omega}}_{\alpha}$ is the Favré-averaged production rate of species $\alpha$, and $x, y$, and $z$ are Cartesian coordinates. The flame index indicates the level of maximum chemical production over all 22 species. The index takes on a value between 0 and 1 , where 0 corresponds to no chemical production and where 1 corresponds to a point where at least one chemical species is produced at its global maximum. By using the maximum chemical production rate over all the species at each point, the flame index remains unbiased toward any single species.

Contours of $\log _{10}(f)$ for cases D584A and S800A are presented in Figs. 6a and 6b, respectively. The index confirms that for dual-mode operation, thin flames anchor near the primary injector orifices, which are stabilized by the leading oblique shock and recirculating fluid directly outside the injectors. Thin flames also burn outside the secondary injector orifices and extend downstream. For case S800A, the flames associated with the primary injectors appear to be fundamentally different than those of the secondary injectors. While there does exist a thin region of combustion near the injectors stabilized by the fuel injection bow shock and fluid recirculation, most of the combustion appears to be distributed from the point of injection to just downstream of the cavity step corner. When compared to the Mach number contours in Fig. 4b, the combustion appears to track the leading shock fronts until a pronounced increase in flame intensity is seen directly behind the point of leading shock-shock interaction. Downstream of this intense region of combustion, a weak distributed flame is observed. The secondary injector flames are similar in nature to those observed in the dual-mode cases, which suggests a relatively thin flame that extends downstream past the injectors and is angled toward the wall. These observations are further supported by analyzing isosurfaces corresponding to $\mathrm{f}=0.1$, which are presented in Figs. 7a and 7b for cases D584A and S800A, respectively. Note that these isosurfaces are colored by mass fraction of $\mathrm{OH}$, which is also a commonly-used flame identifier.

\section{B. Combustion Mode}

In order to isolate the non-premixed combustion data from that of the premixed data, the approach of Yamashita et al. ${ }^{32}$ is used. This method assumes that in non-premixed flames, the gradients of oxidizer and fuel species are oriented in 


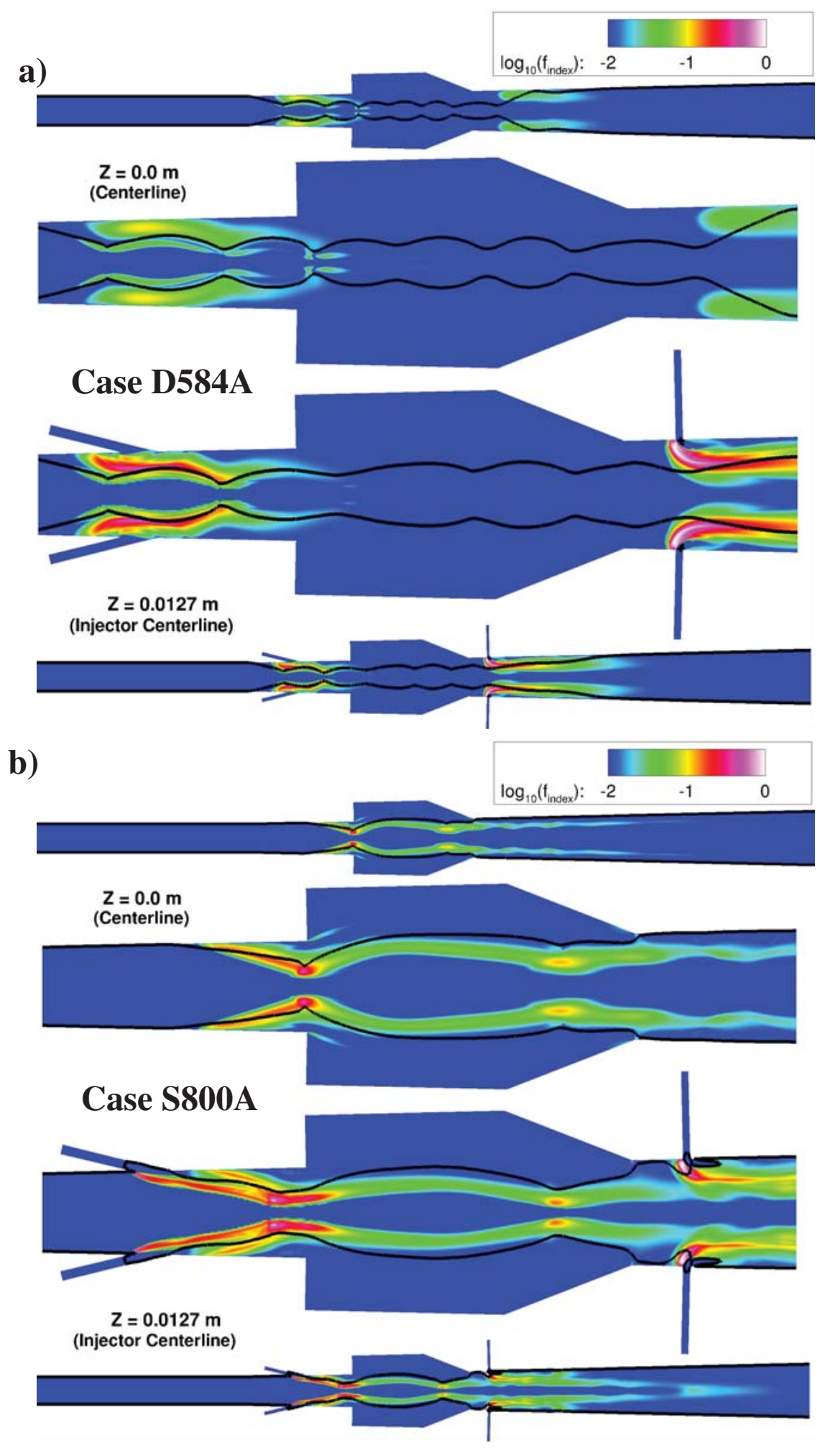

Figure 6. Contours of the logarithm of flame index for simulations D584A (a) and S800A (b). Black lines correspond to the sonic line. 


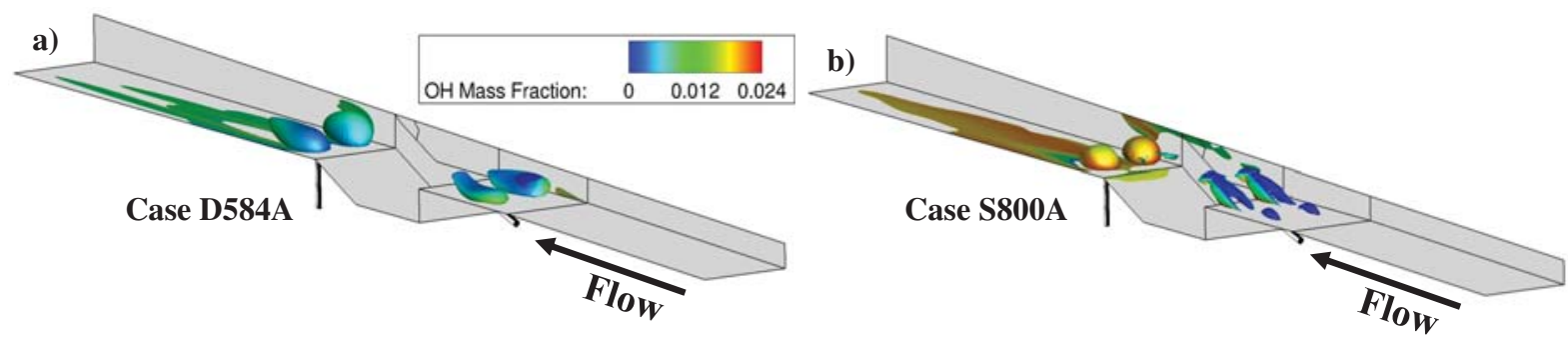

Figure 7. Isosurfaces corresponding to a flame index of 0.1 colored by $\mathrm{OH}$ mass fraction for both primary and secondary injector flames for cases D584A (a) and S800A (b).

opposite directions, while in premixed flames, the gradients are oriented in the same direction. Therefore, by taking the dot product of the gradients and normalizing, the Takeno index, $\Lambda_{T}$, can be computed,

$$
\Lambda_{T}=\frac{\nabla \widetilde{Y}_{\text {oxidizer }} \cdot \nabla \widetilde{Y}_{\text {fuel }}}{\left|\nabla \widetilde{Y}_{\text {oxidizer }} \cdot \nabla \widetilde{Y}_{\text {fuel }}\right|}
$$

where $\widetilde{Y}_{\text {oxidizer }}$ and $\widetilde{Y}_{\text {fuel }}$ are the Favré-averaged oxidizer and fuel species mass fractions, respectively. In the context of RAS, this index indicates the statistically-dominant combustion mode at a given location in the flow field. Since the RAS solution is an averaged representation of the flow field, non-premixed regions of the RAS flow field may exhibit pockets of premixed combustion locally in time and space, and vice versa, which are not captured in this analysis.

The index is recast for the current work using the oxidizer $\left(\mathrm{O}_{2}\right)$ and fuel $\left(\mathrm{CH}_{4}, \mathrm{C}_{2} \mathrm{H}_{4}\right)$ mixture species. In cases where the oxidizer and fuel species are consumed in the same physical direction, the index returns 1.0, which indicates premixed combustion. Alternatively, when the oxidizer and fuel species are consumed in opposite directions, the index returns -1.0 , which indicates non-premixed combustion. By weighting the Takeno index with the flame index, a new index, $\Lambda_{f}$, is formed, which is hereafter referred to as the flame-weighted Takeno index,

$$
\Lambda_{f}=f \Lambda_{T}
$$

The value of $\Lambda_{f}$ ranges from $-1.0<\Lambda_{f}<1.0$ and conveys both the flame intensity and dominant combustion mode at each point in the flow field. Accordingly, $\Lambda_{f}$ is used to focus subsequent analysis first at non-premixed regions of combustion and then at regions of premixed combustion.

The characteristic flow time scale is approximated using the scalar dissipation rate,

$$
\chi=2 D \frac{\partial Z}{\partial x_{j}} \frac{\partial Z}{\partial x_{j}}
$$

where $Z$ is a mixture fraction computed using Bilgers definition, ${ }^{13} D$ is a mass diffusion coefficient, and $x_{j}$ represents the Cartesian coordinates in tensor notation. The scalar dissipation rate has a unit of inverse time and is also representative of a scalar mixing rate. The scalar dissipation rate can be modeled using the approach of Poinsot, who suggests that for RAS applications the scalar dissipation rate plays a similar role to mixture fraction as does the dissipation of turbulent kinetic energy to velocity. ${ }^{29}$ Following this analogy, the scalar dissipation rate can be modeled by,

$$
\chi_{\text {modeled }}=C \underset{\widetilde{\kappa}}{\widetilde{\epsilon}} \widetilde{Z^{\prime \prime 2}}
$$

where $\widetilde{\epsilon}, \widetilde{k}, \widetilde{Z^{\prime \prime 2}}$ are the Favré-averaged turbulence dissipation rate, turbulence kinetic energy, and the mixture fraction variance with $C$ a model constant set to unity. ${ }^{29}$

By using the theoretical upper bound on the mixture fraction variance, the modeled scalar dissipation rate can be rewritten as,

$$
\chi_{\text {modeled }}=\frac{\widetilde{\epsilon}}{\widetilde{k}} \widetilde{Z}(1-\widetilde{Z})
$$


where $\widetilde{Z}$ is the Favré-averaged mixture fraction. The modeled characteristic flow time scale is the inverse of the modeled scalar dissipation rate.

Such modeled scalar dissipation rate and characteristic flow time scale represent their corresponding upper and lower limits, respectively, leading to conservative prediction for these values. An estimate of characteristic time scale associated with the flame chemistry is based on water production rate,

$$
\tau_{\text {chem }}=\frac{\bar{\rho} \widetilde{Y}_{H_{2} O}}{\widetilde{\dot{\omega}}_{H_{2} O}}
$$

where $\widetilde{\dot{\omega}}_{H_{2} O}$ and $\widetilde{Y}_{H_{2} O}$ are the Favré-averaged production rate and mass fraction of water, respectively, and $\bar{\rho}$ is the mixture average density.

Using Eqs. (7) and (8), the local non-premixed Da number, $D a_{n o n-p r e m i x e d}$, can be calculated directly from the simulation dataset,

$$
D a_{\text {non-premixed }}=\frac{1}{\chi_{\text {modeled }} \tau_{\text {chem }}}
$$

In the case of premixed combustion, both the Da and Ka numbers may be used to characterize flame regime; however, care must be taken in the calculation of their constituent components. For a premixed flame, the Da number is typically defined as the ratio of characteristic turbulence and flame time scales. With the laminar flame thickness $\left(l_{F}\right)$ and flame speed $\left(s_{L}\right)$, a characteristic flame time scale may be calculated, and using the integral turbulence length $(l)$ and velocity $\left(u^{\prime}\right)$, a turbulent time scale may be formed. The premixed Da number, $D a_{\text {premixed }}$, is then calculated from,

$$
\text { Da } a_{\text {premixed }}=\frac{\tau_{\text {turb }}}{\tau_{\text {flame }}}=\frac{l / u^{\prime}}{l_{F} / s_{L}}
$$

As Poinsot points out, however, the most appropriate turbulence scale for calculating Da number of a premixed flame is unclear. ${ }^{29}$ Since the current investigation is based on RAS data with model development intended for RAS and LES, the premixed Da number is calculated using the integral turbulence length scale. The laminar flame thickness and laminar flame speed are obtained from the solutions to the freely-propagating laminar premixed flame problem with the unburnt mixture properties corresponding to the average temperature, pressure, and fuel equivalence ratio characterizing the premixed data within the HDCR flow field.

A combustion diagram is presented in Fig. 8, in which Da number is plotted against the flame-weighted Takeno index. In accordance with the preceding discussion, the non-premixed Da number is plotted for data corresponding to $\Lambda_{f}<0$, and the premixed Da number is plotted for $\Lambda_{f}>0$. On each plot, the data point marker size is scaled proportionally to the chemical heat release rate and are colored by the production rate of water. The results are organized by flame location and by mode of operation, where Figs. $8 \mathrm{a}$ and $8 \mathrm{~b}$ correspond to the primary injector flame data for cases D584A and S800A, respectively, and Figs. 8c and 8d correspond to the secondary injector flame data for the same cases, respectively. For each of the figures, the data are sampled from the shaded regions of the flowpath shown above each plot, and data within $3 \%$ of $\Lambda_{f}=0$ are omitted for clarity.

For both the primary and secondary injector flames, Figs. $8 \mathrm{a}$ and $8 \mathrm{c}$ suggest that for case D584A the combustion occurs primarily at high Da numbers $(\mathrm{Da}>>1)$ and in a non-premixed mode $\left(\Lambda_{f}<0\right)$. While limited regions of premixed combustion exist for this case, the heat release is insignificant when compared to that of the non-premixed combustion. These figures suggest that for case D584A, the assumptions made for non-premixed flamelet-models are likely satisfied and that such models may sufficiently predict the combustion physics governing dual-mode operation of the HDCR flowpath. Conversely, analyzing Figs. 8b and 8d for case S800A suggests that the combustion is of a more complex nature for scram-mode flowpath operation. For the primary injectors, the combustion occurs over a range of Da numbers and is split among both non-premixed and premixed modes. In fact, a significant portion of the heat release due to the primary injectors corresponds to premixed regions of combustion occurring near $\mathrm{Da}=1$, thereby suggesting the characteristic flame time scale is on the same order of magnitude as that of the integral turbulence. However, a significant portion of the combustion occurs at high Da numbers in a non-premixed mode, as well. For the secondary injectors, the combustion occurs at a range of Da numbers and primarily in a non-premixed mode. Based on these data, a suitable simulation of the HDCR flowpath for scram-mode operation would likely require both premixed and non-premixed flamelet models, and the assumptions made for these models may only be valid for limited regions of the combustion.

To better understand the nature of the premixed combustion data, modified Borghi combustion regime diagrams are constructed in Figs. 9a and 9b for cases D584A and S800A, respectively, following the approach of Peters. ${ }^{17}$ The 

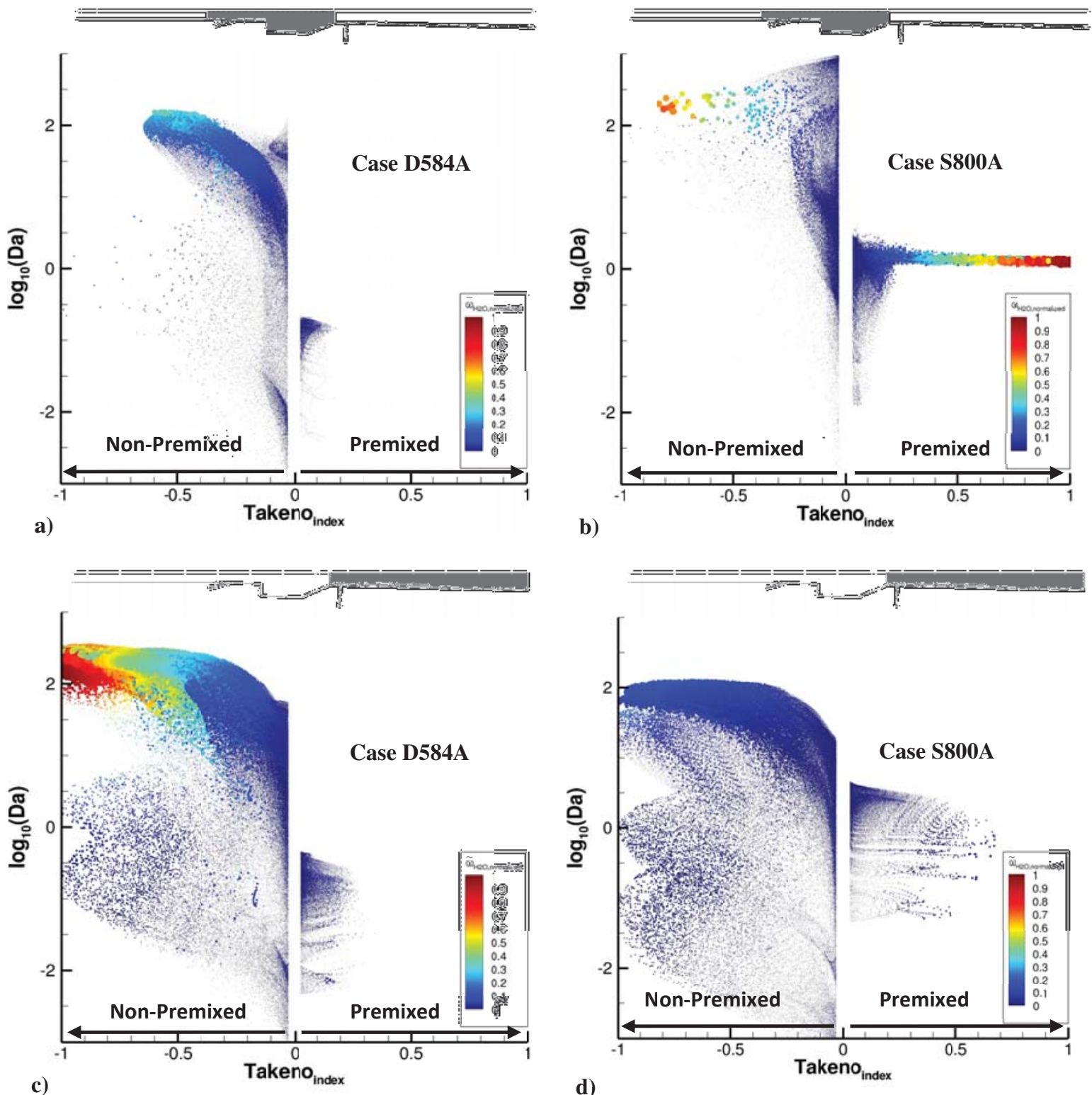

Figure 8. Scatter plots of the Damköhler number versus flame-weighted Takeno index with data point markers sized by chemical heat release and colored by normalized production rate of water. Data are plotted for the primary injector flames in (a) and (b) and for the secondary injector flames in (c) and (d), for cases D584A and S800A, respectively. 

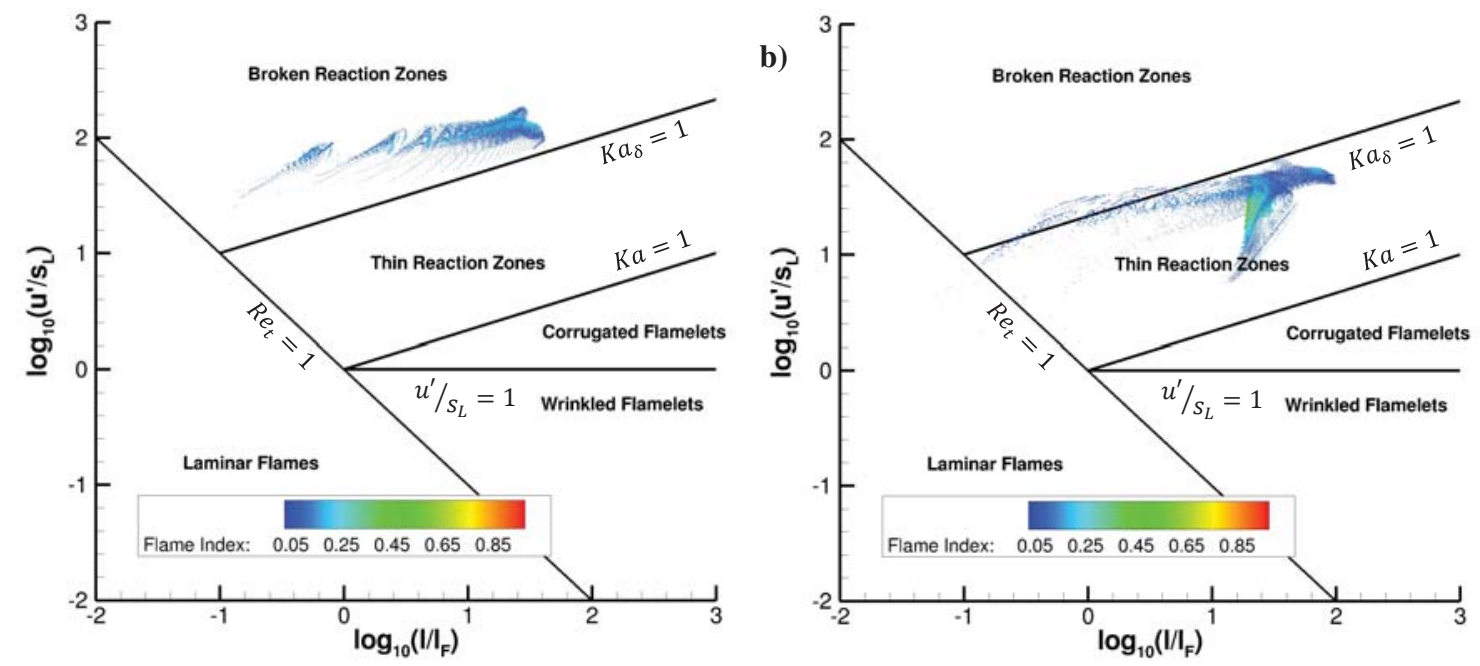

Figure 9. Borghi diagrams for cases D584A (a) and S800A (b), with data point markers colored by flame index and sized proportionally to the chemical heat release rate. Only data for $\Lambda_{f}>0.05$ are plotted.

data point markers are sized proportionally to the chemical heat release rate and colored by flame index. Only data corresponding to the flame index value of $\Lambda_{f}>0.05$ are plotted. The abscissa corresponds to the logarithm of the ratio of the turbulent length scale to that of the flame, and the ordinate is the logarithm of the ratio of the turbulent velocity scale to the laminar flame speed. Both parameters are recast in terms of transported variables and constants as,

$$
\begin{aligned}
& l / l_{F}=\left(\frac{2}{3}\right)^{3 / 2} \frac{\widetilde{\epsilon}}{\widetilde{k}^{1 / 2} l_{F}} \\
& u^{\prime} / s_{L}=\left(\frac{2}{3}\right)^{1 / 2} \frac{\widetilde{k}^{1 / 2}}{s_{L}}
\end{aligned}
$$

Lines corresponding to Ka number of unity, turbulent Reynolds number of unity, and Ka number based on flame reaction zone thickness of unity are overlaid on these figures.

For both cases D584A and S800A, the premixed data reside in the broken reactions and thin reaction regimes, where turbulent Reynolds number $\left(R e_{t}\right)$ and $\mathrm{Ka}$ are greater than one. Within these regimes, the flame thickness is larger than the Kolmogorov scale, which allows Kolmogorov eddies to penetrate the flame partially for the thin reaction regime or completely for the broken reactions regime. More so, within the broken reactions regime, the smallest turbulent eddies may alter the internal flame structure, causing localized extinction, resulting in segmented, broken flame regions. In the case of dual-mode combustion, the heat release corresponding to these premixed data is relatively small compared to that of the non-premixed data. Thus, the flamelet models may still provide reasonable engineering accuracy. However, for the case of scram-mode combustion where much of the premixed combustion occurs within the thin reactions regime, the heat release due to these premixed data is significant. Therefore, these regions of highly-turbulent premixed thin and broken reaction zones challenge the flamelet assumptions and may necessitate alternate modeling techniques. It is important to note that recent work by Savard and Blanquart ${ }^{33}$ suggests flamelet models may be used successfully even for these premixed combustion regimes by using an effective Lewis number mapping. However, further a posteriori simulations are necessary to validate this approach for the current flow field. 


\section{Compressibility}

Building on the success of incompressible flamelet-models, researchers have in recent years embarked on efforts to extend flamelet-models for application to high-speed, compressible reacting flows. These efforts have largely focused on modifying the incompressible flamelet-model formulation to account for the effects of compressibility on the thermo-chemical state space embedded in a flamelet table by either parameterizing the solutions to the incompressible constant-pressure flamelet equations with pressure ${ }^{34}$ or by introducing a pressure scaling on the progress-variable source term when extracting it from the flamelet table. ${ }^{8,35}$ In this section, the effects of compressibility on the combustion are illustrated by investigating the flame structure in mixture fraction space and by examining the effects of pressure.

Since the majority of the combustion occurs in a non-premixed mode, mixture fraction provides a convenient parameterization of the three-dimensional flow field data. In Fig. 10, temperature is plotted in mixture fraction space for cases D584A and S800A and is colored by the logarithm of static pressure. Data corresponding to the primary injector flames are included in Figs. 10a and 10b for cases D584A and S800A, respectively, while data for the secondary injector flames are included in Figs. 10c and 10d for the same cases, respectively. The variation in pressure appears to be generally higher for case S800A, although case D584A exhibits significant variation as well. Thus, not surprisingly, any suitable flamelet-model should account for the effects of pressure and compressibility for application to a dual-mode scramjet combustor.

\section{Wall Heat Losses}

In addition to compressibility concerns, recent research efforts have been directed at including the effects of heat losses in flamelet-models for application to flows with non-adiabatic walls. As with compressibility, researchers have focused on developing modifications to existing incompressible flamelet models to account for wall heat losses using various approaches. ${ }^{36-38}$ In this section, the effect of heat loss on the flame structure is illustrated for the HDCR combustor by analyzing the simulations computed using adiabatic walls and those computed allowing for one-dimensional heat transfer through the walls, thereby making solution differences precisely an effect of wall heat transfer.

The primary mechanism by which wall heat transfer influences the combustion field is via local quenching in the vicinity of the wall. For scramjet engines, in which the core flow is at high velocity and fuel is injected through the walls, a considerable amount of fuel maybe entrained in the slow-moving near-wall regions. As a result, the fuel has sufficient time to mix with oxidizer and react, thereby creating intense regions of combustion near the wall surfaces. In Figs. 11a and 11b, temperature conditionally-averaged on mixture fraction is plotted for cases D584A and D584I and cases S800A and S800I, respectively. Also included on both figures is the temperature variance. For both dual-mode and scram-mode operation, the effect of heat loss through the walls is a decrease in average stoichiometric temperature and an increase in temperature variance, which is in accord with the notion that heat loss through the walls results in regions of quenched combustion and reduced boundary layer autoignition. Further, the effect of heat losses through the walls can be clearly seen in Figs. 12a and $12 \mathrm{~b}$ for dual-mode operation and in Figs. 12c and 12d for scram-mode operation by examining the near-wall data. In Fig. 12, the static temperature is plotted in mixture fraction space, and data are colored by the velocity magnitude, $V_{s}$. By examining the minimum velocity magnitude data, one can directly observe the effect of near-wall flame quenching by heat losses through the wall; these quenched, near-wall data for cases D584I and S800I reside among the higher temperature data in cases D584A and S800A, respectively. While these differences are pronounced and may possibly suggest the inclusion of such effects in a general compressible flamelet model, simulations with adiabatic walls yielded more accurate solutions when compared to experimental static pressure data for the HDCR, thereby suggesting the aggregate effect of wall heat transfer on the combustion is limited.

\section{Compressible Flamelet Model Methodology}

Since the analysis presented in the previous section suggests that the assumptions of flamelet-models are largely valid for the HDCR combustor during dual-mode operation, and potentially for scram-mode operation, subsequent discussion considers some of the practical issues associated with implementing and applying a flamelet-model to a high-speed, compressible turbulent combusting flow. In this section, a compressible flamelet model methodology is discussed that addresses the problem of boundary condition specification and corresponding table construction.

For compressible applications of flamelet-generated manifolds, typical parameterizations like $(Z, \chi)$ or $\left(Z, C_{P G}\right)$ 

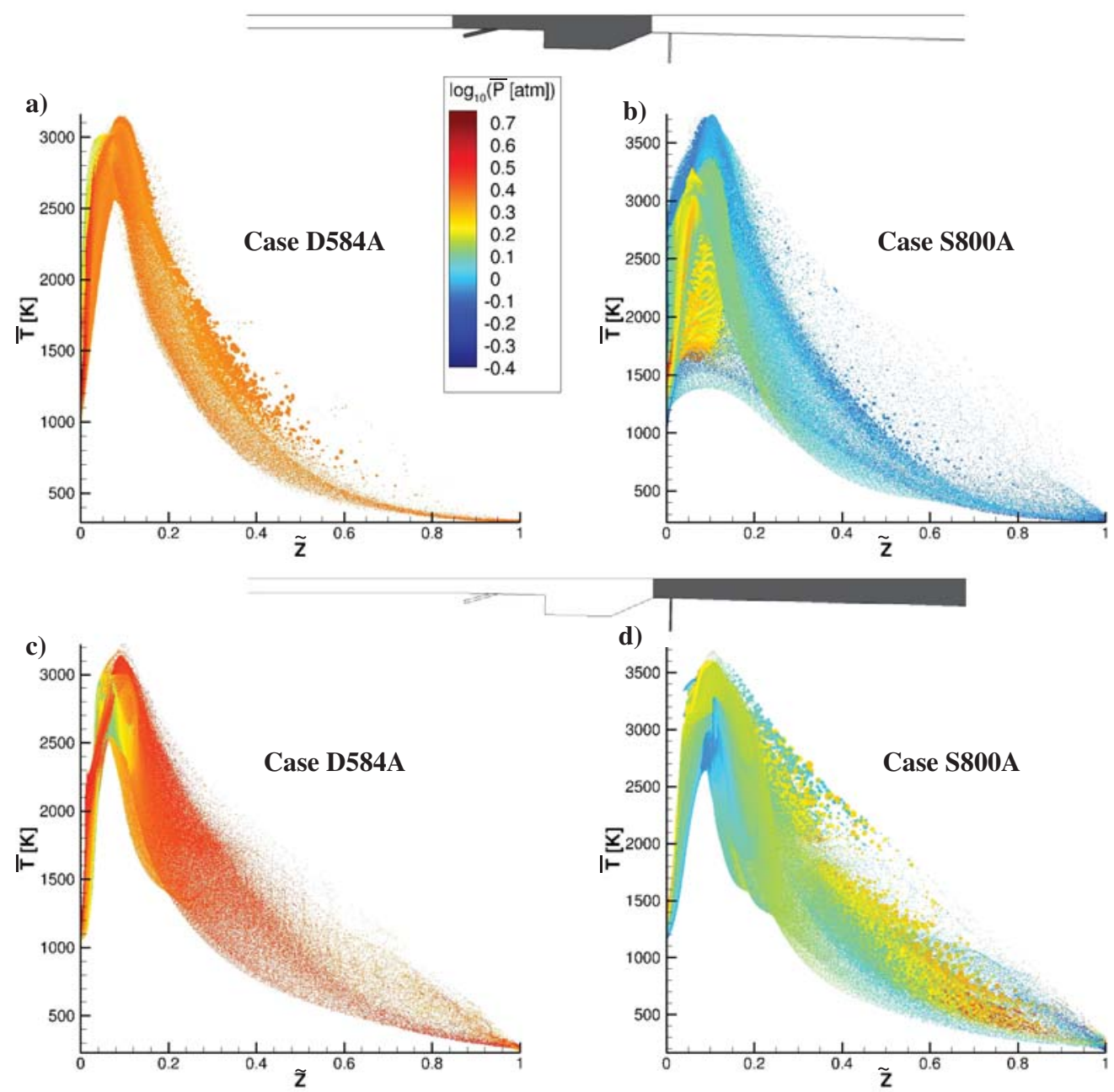

Figure 10. Scatter plot of the static temperature versus mixture fraction with data point markers colored by the logarithm of static pressure and sized proportionally to the chemical heat release rate for (a) case D584 and (b) case S800A primary injector flames and for (c) case D584A and (d) case S800A secondary injector flames. 
a)

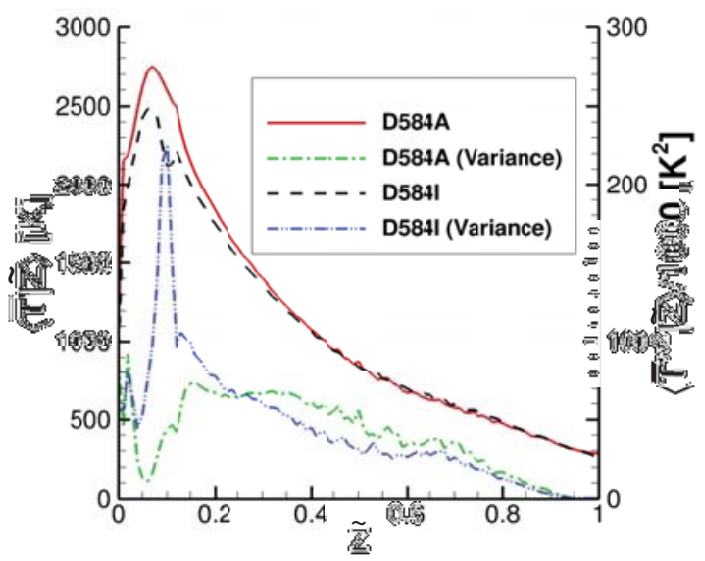

b)

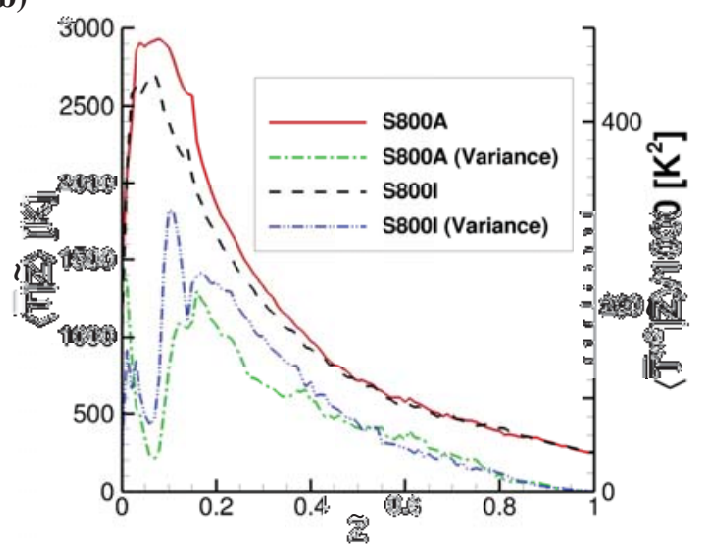

Figure 11. Conditionally-averaged static temperature and its variance versus mixture fraction for dual-mode (a) and scram-mode (b) cases.

are generally inadequate due to the wide variations in pressure and total energy. To account for these effects, a suitable manifold must also include pressure, and likely enthalpy, as parameterizing quantities. However, the process of specifying applicable ranges for some of the quantities a priori is unclear. For example, since pressure varies with flowpath geometry, across shocks, and with heat addition, determining the appropriate pressures at which to build a flamelet table for a scramjet combustor is impossible without prior knowledge of the flow field. In this regard, a compressible flamelet model is fundamentally different from conventional incompressible flamelet models in that prior knowledge of the flow field solution is required. A further complication is that pressure and enthalpy are not conveniently defined to vary between zero and unity like mixture fraction and progress variable. One could argue that if computational resources were not a constraint, one could simply build a table across all possible pressure and enthalpy levels; however, while this may be true, the objective of flamelet models is to lessen the cost of performing a turbulent reacting combustion simulation. As the flamelet table grows in dimension and span, the cost of performing lookup operations grows such that the cost of the flamelet model may exceed that of higher-fidelity approaches. Therefore, a new flamelet model methodology is necessary.

The critical component of such a methodology, apart from the details of the model itself, is the use of the a priori data in building a suitable flamelet table. After determining the applicability of flamelet models for a given flow field, a priori data regarding the flames must be elicited from a prior simulation or available experimental data. At a minimum, fuel and oxidizer temperatures (or enthalpies) and pressures must be collected for regions of the flow field where a flame index indicates the presence of combustion. With this data, one may construct probability density functions (PDFs) to determine the range of flamelet conditions required to model the combustion. The flamelet table is subsequently built by solving the flamelet equations across these conditions and by parameterizing the state space by mixture fraction, progress variable, pressure, and enthalpy. If turbulence-chemistry interactions are modeled, the state space must further be parameterized by mixture fraction and progress variable variances. At runtime, transport equations are solved for each of these parameterizing variables. For the case of multiple injectors, it may be prudent to tailor the analysis to each set independently and to determine whether a multiple flamelet approach is best suited. ${ }^{39,40}$

As a first step in estimating the representative flamelet conditions embedded in the HDCR combustor, all data points within $1 \%$ of pure oxidizer and pure fuel according to mixture fraction were isolated from the solution and from each other. Next, these data were split into two groups according to whether the data resided in the primary or secondary injector flames. PDFs were constructed for pressure, temperature, and fuel and oxidizer mass fractions. PDFs for pressure and temperature for cases D584A and S800A are presented in Fig. 13. For both dualmode and scram-mode operation, the fuel temperatures remain fairly constant at their nominal values, while the oxidizer temperatures vary considerably and exhibit multimodal distributions. For the primary injector flames, the fuel pressures are distributed tightly around their nominal values, whereas the oxidizer pressures exhibit multimodal distributions. In the case of the secondary injector flames, both the fuel and oxidizer pressures show multimodal distributions. While the most representative samplings of these distributions are not immediately apparent, bounding conditions for these temperatures and pressures can be quickly determined by examining the span of each PDF. 

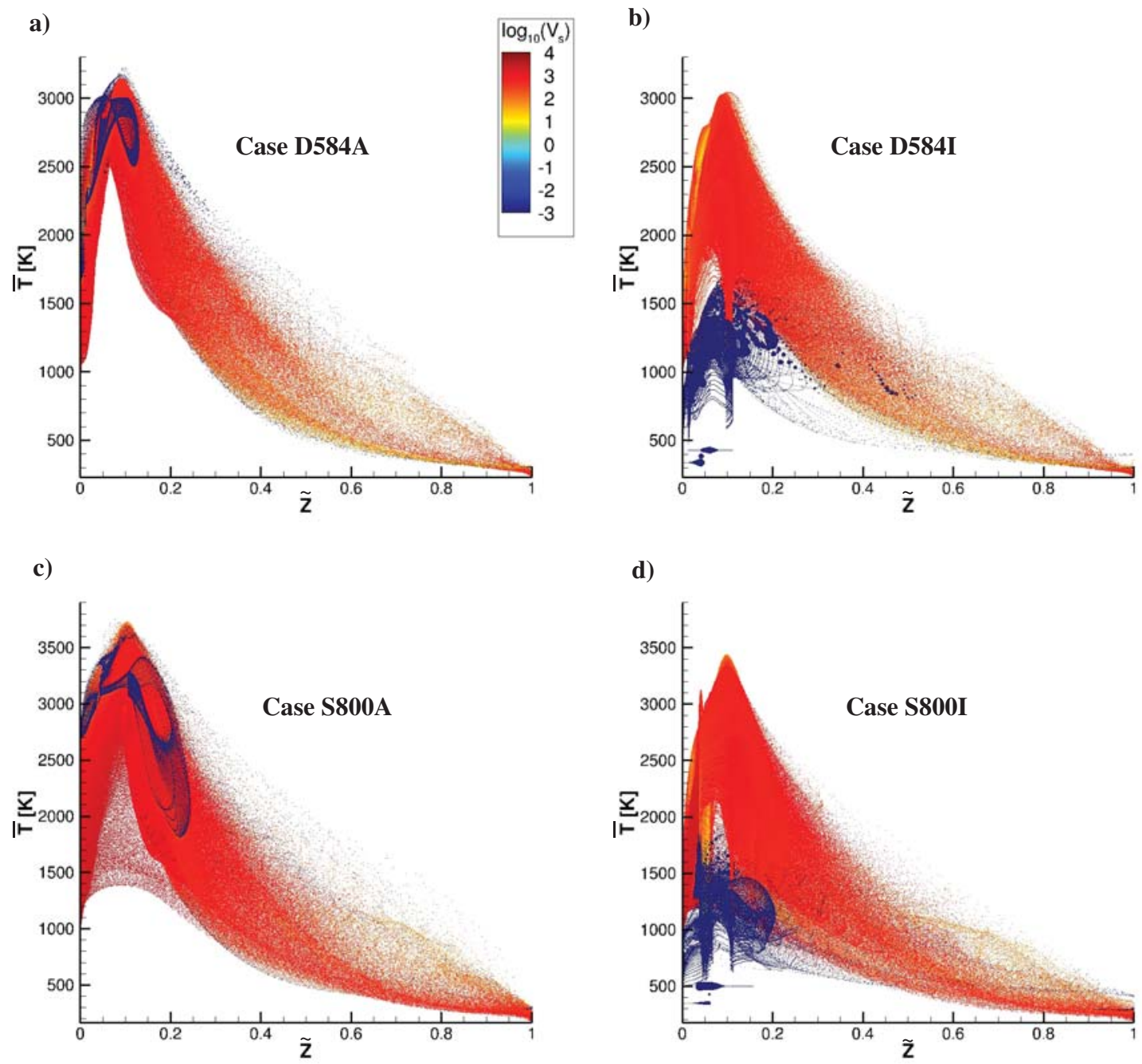

Figure 12. Scatter plot of static temperature versus mixture fraction with data point markers colored by the logarithm of velocity magnitude for cases (a) D584A, (b) D584I, (c) S800A, and (d) S800I. Dark blue scatter data correspond to the near-wall combustion. 

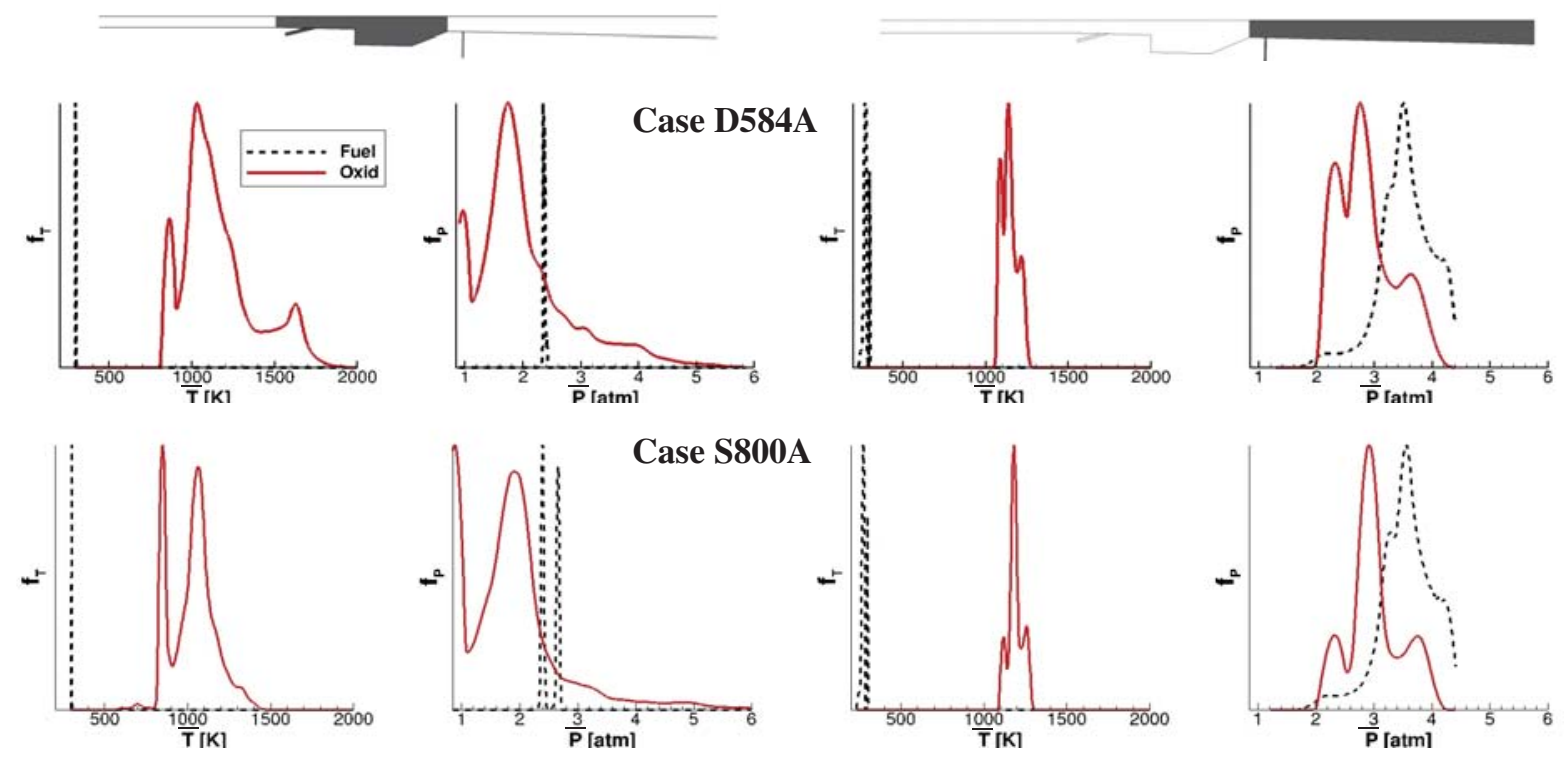

Figure 13. PDFs of static temperature and pressure $\left(f_{T}\right.$ and $f_{P}$, respectively) for fuel $(Z>0.99)$ and oxidizer $(Z<0.01)$ conditions for cases D584A (top) and S800A (bottom). Regions from which the data are sampled are shown above the respective plots, with the leftmost representing the primary injector flames and the rightmost representing the secondary injector flames.

Bounding conditions on fuel and oxidizer temperature and pressure based on these PDFs are summarized in Table 2. A priori sensitivity studies are likely necessary to determine the minimum number of enthalpy and pressure levels required for a given simulation within these bounding values.

\section{Conclusions and Future Work}

As a first effort toward developing a compressible flamelet model for application to dual-mode scramjet combustors, an a priori analysis of the HDCR flowpath was performed to determine the validity of flamelet-model assumptions. RAS of the HDCR was first performed for dual-mode and scram-mode operating conditions, and the wall static pressure data were compared to values obtained experimentally. The simulations utilized a 22 -species, 18 -step, chemical reaction mechanism for the combustion of an ethylene and methane fuel mixture, which allowed for the reconstruction of mixture fraction using Bilgers definition. The flames were characterized using a flame-weighted Takeno index and combustion regime diagrams, which suggested that for dual-mode flowpath operation, combustion occurred at relatively high Damköhler numbers $(\mathrm{Da}>>1)$ and in a non-premixed mode. These results also suggested that for scram-mode flowpath operation, the primary injector flames exhibited mixed combustion modes, in which significant

Table 2. Approximate bounding fuel and oxidizer temperature and pressures derived from corresponding PDFs for simulated test cases.

\begin{tabular}{cccccc} 
Case & $\begin{array}{c}\text { Injector } \\
\text { Location }\end{array}$ & $\begin{array}{c}\text { Fuel } \\
\text { Temperature } \\
\text { Range }[\mathrm{K}]\end{array}$ & $\begin{array}{c}\text { Fuel } \\
\text { Pressure } \\
\text { Range }[\mathrm{atm}]\end{array}$ & $\begin{array}{c}\text { Oxidizer } \\
\text { Temperature Range } \\
{[\mathrm{K}]}\end{array}$ & $\begin{array}{c}\text { Oxidizer } \\
\text { Pressure Range } \\
{[\mathrm{atm}]}\end{array}$ \\
\hline D584A & Primary & $300.0-300.0$ & $2.25-2.50$ & $800.0-1900.0$ & $0.90-5.80$ \\
D584I & Secondary & $230.0-300.0$ & $1.60-4.40$ & $1050.0-1275.0$ & $2.00-4.30$ \\
S800A & Primary & $300.0-300.0$ & $2.30-2.70$ & $550.0-1450.0$ & $0.85-6.00$ \\
S800I & Secondary & $230.0-300.0$ & $1.70-4.40$ & $1100.0-1300.0$ & $2.00-4.20$
\end{tabular}


heat release was found in regions of both non-premixed and premixed conditions and at both moderate $(\mathrm{Da}=1)$ and high $(\mathrm{Da}>>1)$ Damköhler numbers. Detailed analysis of the premixed combustion data suggested thin and broken reaction zones, as evidenced by Borghi combustion regime diagrams. These findings suggested that a hybrid nonpremixed/premixed flamelet-model may be necessary to model the flames for scram-mode flowpath operation. The effects of compressibility and heat losses were found to have a significant effect on the combustion, thereby suggesting that a suitable flamelet manifold should be parameterized by pressure and enthalpy. An analysis of the temperature and pressure at theoretical flamelet boundaries further supported the necessity of including pressure and enthalpy as manifold dimensions and suggested that the standard practice of using a single set of flamelet boundary conditions is an approximation.

The current analysis supports the development of a compressible flamelet model for high-speed reacting flows. Work is currently underway to revisit some of the conclusions drawn here from RAS by performing LES of the HDCR using the same 22 -species chemical reaction mechanism. Building upon the current a priori work, also underway are a priori analyses of RAS solutions post-processed utilizing a flamelet table, as described in Section V. This new analysis represents the best-case-scenario for the performance of the flamelet model and permits rapid testing of progress variable definitions, pressure level sensitivities, and boundary condition effects. The results of these calculations will be used to guide the development of a compressible flamelet model for application to high-speed reacting flow fields. Finally, a posteriori analysis utilizing proposed flamelet model will be performed using both RAS and LES of the HDCR.

\section{Acknowledgments}

This work was supported by a NASA Space Technology Research Fellowship (training grant NNX11AM86H), with additional support provided by the Virginia Space Grant Consortium and by a Virginia Commonwealth Fellowship. The authors are grateful for the helpful discussions with Dr. Robert Baurle and Mike Bynum during the course of this study. Computational resources were provided by the NASA Advanced Supercomputing Division.

\section{References}

${ }^{1}$ Smart, M.K., Hass, N.E., and Paull, A., "Flight Data Analysis of the HyShot 2 Scramjet Flight Experiment," AIAA J., Vol. 44, No. 2, 2006, pp. 2366-2375.

${ }^{2}$ Hass, N.E., Smart, M.K., and Paull, A., "Flight Data Analysis of HyShot 2," in AIAA/CIRA 13th International Space Planes and Hypersonics Systems and Technologies, Capua, Italy, 2005.

${ }^{3}$ McClinton, C.R., Rausch, V.L., Nguyen, L.T., and Sitz, J.R., "Preliminary X-43 Flight Test Results," Acta Astronautica, Vol. 57, No. 2, 2005, pp. 266-276.

${ }^{4}$ McClinton, C.R., "X-43 Scramjet Power Breaks the Hypersonic Barrier: Dryden Lectureship in Research for 2006," in 44th AIAA Aerospace Sciences Meeting and Exhibit, Reno, NV, 2006.

${ }^{5}$ Dolvin, D., "Hypersonic International Flight Research and Experimentation (HIFiRE)," in 15th AIAA International Space Planes and Hypersonic Systems and Technologies Conference, Reno, NV, 2008.

${ }^{6}$ Jackson, K.R., Gruber, M.R., and Barhorst, T.F., "The HIFiRE Flight 2 Experiment: An Overview and Status Update," in 45th AIAA/ASME/SAE/ASEE Joint Propulsion Conference and Exhibit, Denver, CO, 2009.

${ }^{7}$ Rockwell, R.D., Goyne, C.P., Rice, B.E., Tatman, B.J., Smith, C., Kouchi, T., McDaniel, J.C., Fulton, J.A., and Edwards, J.R., "CloseCollaborative Experimental and Computational Study of a Dual-Mode Scramjet Combustor," in 50th AIAA Aerospace Sciences Meeting, Nashville, TN, 2012.

${ }^{8}$ Pecnik, R., Terrapon, V., Ham, F., Iaccarino, G., and Pitsch, H., "Reynolds-Averaged Navier-Stokes Simulations of the HyShot II Scramjet," AIAA J., Vol. 50, 2012, pp. 1717-1732.

${ }^{9}$ Fureby, C., Chapius, M., Fedina, E., and Karl, S., "CFD Analysis of the HyShot II Scramjet Combustor," Proc. Combust. Inst., Vol. 33, No. 2, 2011, pp. 2399-2405.

${ }^{10}$ Larsson, J., "Large Eddy Simulations of the HyShot II Scramjet Combustor Using a Supersonic Flamelet Model," in 48th AIAA/ASME/SAE/ASEE Joint Propulsion Conference \& Exhibit, Atlanta, GA, 2012.

${ }^{11}$ Fulton, J.A., Edwards, J.R., Hassan, H.A., Rockwell, R.D., Goyne, C.P., McDaniel, J.C., Smith, C., Cutler, A.D., Johansen, C., Danehy, P.M., and Kouchi, T., "Large-Eddy/Reynolds-Averaged Navier-Stokes Simulations of a Dual-Mode Scramjet Combustor," in 50th AIAA Aerospace Sciences Meeting, Nashville, TN, 2012.

${ }^{12}$ Fulton, J.A., Edwards, J.R., Goyne, C.P., McDaniel, J.C., and Rockwell, R.D., "Numerical Simulation of Flow in a Dual-Mode Scramjet Combustor," in 41 st AIAA Fluid Dynamics Conference and Exhibit, Honolulu, HI, 2011.

${ }^{13}$ Bilger, R.W., Starner, S.H., and Kee, R.J., "On Reduced Mechanisms for Methane-Air Combustion in Nonpremixed Flames," Combust. Flame, Vol. 80, 1990, pp. 135-149.

${ }^{14}$ Sung, C.J., Law, C.K., and Chen, J.Y., "Further Validation of an Augmented Reduced Mechanism for Methane Oxidation: Comparison of Global Parameters and Detailed Structures," Combust. Sci. Technol., Vol. 156, 2000, pp. 201-200. 
${ }^{15}$ Pope, S.B., "Computationally Efficient Implementation of Combustion Chemistry using in situ Adaptive Tabulation," Combust. Theor. Model., Vol. 1, No. 1, 1997, pp. 41-63.

${ }^{16}$ Peters, N., "Laminar Diffusion Flamelet Models in Non-Premixed Turbulent Combustion," Prog. Energy Combust. Sci., Vol. 10, No. 3, 1984, pp. 319-339.

${ }^{17}$ Peters, N., "Laminar Flamelet Concepts in Turbulent Combustion,” Proc. Combust. Inst., Vol. 21, 1986, pp. 1231-1250.

${ }^{18}$ van Oijen, J.A., Flamelet-generated manifolds: Development and application to premixed laminar flames, Ph.D. Thesis, Eidenhoven Technical University, Eidenhoven, Netherlands, 2002.

${ }^{19}$ Cabell, K., Hass, N.E., Storch, A., and Gruber, M., "HIFiRE Direct-Connect Rig (HDCR) Phase I Scramjet Test Results from the NASA Langley Arc-Heated Scramjet Test Facility," in 17th AIAA International Space Planes and Hypersonic Systems and Technologies Conference, San Francisco, CA, 2011.

${ }^{20}$ Guy, R.W., Rogers, R.C., Puster, R.L., Rock, K.E., and Diskin, G.S., "The NASA Langley Scramjet Test Complex," in 32nd ASME, SAE, and ASEE, Joint Propulsion Conference and Exhibit, Lake Buena Vista, FL, 1996.

${ }^{21}$ Storch, A., Bynum, M., Liu, J., and Gruber, M., “Combustor Operability and Performance Verification for HIFiRE Flight 2," in 17th AIAA International Space Planes and Hypersonic Systems and Technologies Conference, San Francisco, CA, 2011.

${ }^{22}$ Ferlemann, P.G., "Forebody and Inlet Design for the HIFiRE 2 Flight Test," in JANNAF Airbreathing Propulsion Subcommittee Meeting, Boston, MASS, 2008

23" Viscous Upwind ALgorithm for Complex Flow ANalysis (VULCAN)," http://vulcan-cfd.larc.nasa.gov, 2014.

${ }^{24}$ Wilcox, D.C., "Wall Matching, a Rational Alternative to Wall Functions," in 27th Aerospace Sciences Meeting, Reno, NV, 1989.

${ }^{25}$ Menter, F.R., "Two-Equation Eddy-Viscosity Turbulence Models for Engineering Applications," AIAA J., Vol. 32, No. 8, 1994, pp. 15981605.

${ }^{26}$ Edwards, J.R., "A Low-Diffusion Flux-Splitting Scheme for Navier-Stokes Calculations," Comput. Fluids., Vol. 26, No. 6, 1997, pp. 635659.

${ }^{27}$ Krist, S., Biedron, R., and Rumsey, C., "CFL3D User's Manual (Version 5.0),” NASA TM 208444, NASA, 1998.

${ }^{28}$ Luo, Z., Yoo, C.S., Richardson, E.S., Chen, J.H., Law, C.K., and Lu, T.F., "Chemical Explosive Mode Analysis for a Turbulent Lifted Ethylene Jet Flame in Highly-Heated Coflow," Combust. Flame, Vol. 159, No. 1, 2012, pp. 265-274.

${ }^{29}$ Poinsot, T. and Veynante, D., Theoretical and Numerical Combustion, R.T. Edwards, Inc., Philadelphia, PA, 2nd ed., 2005.

${ }^{30}$ Borghi, R., "On the Structure of Turbulent Premixed Flames," Recent Advances in Aeronautical Science, 1984, pp. 117-138.

${ }^{31}$ Lacaze, G., Richardson, E., and Poinsot, T., "Large Eddy Simulation of Spark Ignition in a Turbulent Methane Jet," Combust. Flame, Vol. 156, 2009, pp. 1993-2009.

${ }^{32}$ Yamashita, H., Shimada, M., and Takeno, T., "A Numerical Study on Flame Stability at the Transition Point of Jet Diffusion Flames," Proc. Combust. Inst., Vol. 26, 1996, pp. 27-34.

${ }^{33}$ Savard, B. and Blanquart, G., "An A Priori Model for the Effective Species Lewis Numbers in Premixed Turbulent Flames," Combust. Flame, Vol. In Press, 2014.

${ }^{34}$ Bekdemir, C., Somers, L., and de Goey, L., "Modeling Diesel Engine Combustion using Pressure Dependent Flamelet Generated Manifolds," Proc. Combust. Inst., Vol. 33, No. 2, 2011, pp. 2887 - 2894.

${ }^{35}$ Larsson, J., Vicquelin, R., and Bermejo-Moreno, I., "Large Eddy Simulations of the HyShot II Scramjet," in Annual Research Briefs, Center for Turbulence Research, Stanford University, Stanford, CA, 2011.

${ }^{36}$ Sozer, E., Hassan, E., Yun, S., Thakur, S., Wright, J., Ihme, M., and Shyy, W., "Turbulence-Chemistry Interaction and Heat Transfer Modeling of H2/O2 Gaseous Injector Flows," in 48th AIAA Aerospace Sciences Meeting and Exhibit, Orlando, FL, 2010.

${ }^{37}$ Lee, D.J., Ihme, M., Thakur, S., and Shyy, W., "LES of a Gaseous H2/O2 Rocket Injector: Wall Heat Transfer Modeling," in 13th International Conference on Numerical Combustion, Corfu, Greece, 2011.

${ }^{38} \mathrm{Wu}, \mathrm{H}$. and Ihme, M., "Modeling of Unsteady Heat Transfer in Flame-Wall Interaction," in 66th Division of Fluid Dynamics Meeting of the American Physical Society, Pittsburgh, PA, 2013.

${ }^{39}$ Barths, H., Hasse, C., Bikas, G., and Peters, N., "Simulation of Combustion in Direct Injection Diesel Engines Using an Eulerian Particle Flamelet Model," Proc. Combust. Inst., Vol. 28, No. 1, 2000, pp. 1161-1167.

${ }^{40}$ Felsch, C., Gauding, M., Hasse, C., Vogel, S., and Peters, N., "An Extended Flamelet Model for Multiple Injections in DI Diesel Engines," Proc. Combust. Inst., Vol. 32, No. 1, 2009, pp. 2775-2783. 